\title{
Direct measurement and prediction of bulk density on alluvial soils of central Chile
}

Manuel Casanova ${ }^{1 *}$, Elizabeth Tapia ${ }^{1}$, Oscar Seguel $^{1}$, and Osvaldo Salazar ${ }^{1}$

\section{ABSTRACT}

The significance of soil bulk density $\left(\rho_{\mathrm{b}}\right)$ as a key indicator of soil quality was examined in this study. Bulk density values obtained by direct methods (clod, cylinder, and excavation) with three sample sizes (small, medium, and large) were compared with those obtained by 10 published pedotransfer functions (PTFs) for two alluvial soils (a massive fine-textured Fluventic Haploxeroll and an aggregated, coarse-textured Fluventic Haploxerept) of central Chile. With the exception of small cylinders in fine-textured soil, there were nonsignificant differences between the methods and sample sizes assessed. On the coarse-textured soil, there were nonsignificant differences between the excavation and clod methods, but mediumsized cylinders differed from other cylinder sizes. In general, the clod technique tended to give higher values than the other methods. Using basic information (texture and organic matter/C content) from the existing PTFs for both sites, a better fit for coarse-textured than fine-textured soils was obtained. This indicates that it is necessary to define a set of locally calibrated PTFs that address the complexity of the soil resource throughout Chile.

Key words: Alluvial soils, organic carbon, pedotransfer function, texture.

${ }^{1}$ Universidad de Chile, Facultad de Ciencias Agronómicas, Casilla 1004, Santiago, Chile. *Corresponding author (mcasanov@uchile.cl).

Received: 25 June 2015.

Accepted: 16 October 2015.

doi:10.4067/S0718-58392016000100015

\section{INTRODUCTION}

The variability in soil quality influences mainly biogeochemical cycling, biodiversity, and agricultural productivity. However, soil quality cannot be directly determined, but can be inferred by measuring soil physical, chemical and biological properties. Soil bulk density $\left(\rho_{\mathrm{b}}\right)$ describes the spatial arrangement of the solid particles that compose soil matrix, providing an indication of basic soil quality index (Chan, 2005). As a key state variable, $\rho_{\mathrm{b}}$ provides valuable information relating to porosity, compaction, and penetration resistance of soil (Horn et al., 2003). Linked to soil hydraulic properties, it is vital in predicting rainfall-runoffinfiltration-erosion relationships, heat and gas exchange, seedling emergence, root growth, and crop yield (Siegel-Issem et al., 2005; Assouline, 2011). In addition to physical and biological roles, it is also used to convert soil organic carbon (SOC) and other nutrients from content (e.g. $\mathrm{g} \mathrm{kg}^{-1}$ soil) into stock (e.g. $\mathrm{kg} \mathrm{m}^{-2}$ ) at any specified depth. However, the measurement technique used may have dramatic implications for calculating carbon mass in soils (Throop et al., 2012).

Bulk density is not an intrinsic soil property but depends on external conditions, with changes associated with a variety of factors and with various natural and anthropogenic processes (Zeng et al., 2013). It can also change as a consequence of root growth, rainfall or normal traffic (Drewry, 2006). Both wettingdrying and freezing-thawing cycles after tillage may also cause the $\rho_{\mathrm{b}}$ to increase because of natural soil reconsolidation (Assouline, 2011; Hu et al., 2012).

Soil bulk density is actually a function rather than a single value where only soil mass remains unaltered, but the water status of the sample must be stated when soil volume is measured (Grossman and Reinsch, 2002). While measuring the mass of a soil sample is simple and routine, measuring its volume generates a degree of uncertainty (Hartge and Ellies, 1999). The determination methods commonly used for determining soil volume have their particular limitations and their suitability for specific conditions. The choice of assessment method depends on the purpose of the measurement, the required accuracy and precision, the need for repeated measurements at the same location, costs, operator expertise, and equipment/time availability (Cresswell and Hamilton, 2002). Besides the disturbance of the soil structure caused by the particular method, other constraints in $\rho_{\mathrm{b}}$ assessment are the size and representativity of the sample. While several techniques for determination of $\rho_{\mathrm{b}}$ have been developed (Grossman and Reinsch, 2002), no single standard exists. 
Recent technological advances have allowed the development of many new non-destructive methods, such X-ray computed tomography (Helliwell et al., 2013), thermo-time domain reflectometry sensors (Liu et al., 2008) and automated 3-dimensional laser scanning (Rossi et al., 2008) to determine $\rho_{\mathrm{b}}$. However, acquiring and employing such new technology can be complex and very expensive and access to it may be limited.

In general, both direct (requiring removal and weighing of soil from a known or measured volume) and indirect (transmitting or scattering instruments with empirical calibration that does not involves soil removal) methods for measuring $\rho_{\mathrm{b}}$ are used. Although there is general agreement between the results of direct and indirect methods (Chan, 2005), larger differences among direct methods (cylinder core, clod, and excavation) have been reported (Timm et al., 2005).

Pedotransfer functions (PTFs) have been gaining widespread recognition for their ability to predict $\rho_{\mathrm{b}}$ using extractable available soil databases (Tranter et al., 2007; Al-Qinna and Jaber, 2013). At least four factors affect the performance of a PTF in simulations: the accuracy of basic soil data used as inputs in PTFs, the accuracy of PTF itself, specific features of the simulation model, and the output used as a functional criteria (Donatelli et al., 2004). Although preliminary studies showed that soil organic matter (SOM) has an important effect on $\rho_{\mathrm{b}}$, it has since been observed that soil texture plays a major role in controlling $\rho_{\mathrm{b}}$ and SOM is a minor component (Rawls, 1983; Al-Qinna and Jaber, 2013). Moreover, more recent research (Hollis et al., 2012) reports that other physical and chemical soil properties are involved. Regardless of the methodology used to derive them, PTFs are developed based on specific databases. Thus it is important to evaluate how well PTFs perform when applied outside the range of the data used to derive them.

The aims of this work were to compare three direct methods for determining soil bulk density (core, clod, and excavation) using three sample sizes on two alluvial soils characterized by crystalline mineralogy, and compare the performance of 10 published PTFs with those three direct methods. No previous attempts have been made to test and compare the applicability of $\rho_{\mathrm{b}}$ PTFs for Chilean soils.

\section{MATERIALS AND METHODS}

The two selected soils are located in Mediterranean central Chile, both with an alluvial origin. They are classified (Soil Survey Staff, 2014) as a Fluventic Haploxeroll (MPC, Mapocho soil series; 33³0'11" S, 7049'36” W, 452 m a.s.1.) and a Fluventic Haploxerept (RLV, Rinconada Lo Vial soil series; 33³0'04" S, 7049'39” W, 455 m a.s.1.) and, their cartographic units extend over 5700 and 2400 ha, respectively, in the Metropolitan Region, Chile. As deep soils without coarse fragments and developed on a gentle slope, differences between the soils depend on the geomorphic position, with coarse- and fine-textured pedons occurring in the higher (RLV) and lower (MPC) alluvial terraces, respectively. Moreover, while both soils have been used under conventional tillage during the last $14 \mathrm{yr}$, in contrast to the MPC profile (massive fine-textured soil), the soil structure in the RLV profile is well-developed.

The prevailing climate conditions are semi-arid, with a thermic soil temperature regime (mean annual temperature: $14.2{ }^{\circ} \mathrm{C}$ ), a xeric soil moisture regime (annual mean precipitation: $270 \mathrm{~mm}$ ) and large inter-annual variations in precipitation (Montecinos and Aceituno, 2003; Pizarro et al., 2012).

The field study was carried out in $30 \mathrm{~m}^{2}$ experimental plots (Figure 1) within a single mapping unit of each soil series, which were divided into 100 micro-plots $(0.5 \mathrm{~m} \times$ $0.5 \mathrm{~m})$. Soil bulk density $\left(\rho_{\mathrm{b}}\right)$ was measured in situ with random sampling and 10 replicates, and below the plough layer $(30 \mathrm{~cm})$ produced by conventional tillage, using three direct methods (cylinder, clod, and excavation) as described by Sandoval et al. (2012). Additionally three sample sizes were tested, metal cylinders $5 \mathrm{~cm}$ in height $(\mathrm{H})$ and with diameter (D) of 5.0, 7.3, and $10.0 \mathrm{~cm}$ were driven into the soil manually with a hammer and used to extract soil cores within the range $1 / 2<\mathrm{H} / \mathrm{D}<2$ as suggested by Pansu et al. (2001). Natural soil clods $(2.5,3.0$, and $4.0 \mathrm{~cm}$ diameter for RLV soil and 4.3, 4.7, and $5.2 \mathrm{~cm}$ diameter for MPC soil) were placed in a hair net and dipped into molten paraffin $\left(0.8 \mathrm{~g} \mathrm{~cm}^{-3}\right.$ density). Finally, $\rho_{\mathrm{b}}$ was determined in irregular semi-spherical holes with sizes excavated within the range suggested by Grossman and Reinsch (2002) and Brye et al. (2004) (3, 4, and $6 \mathrm{~cm}$ cavity depth/6, 8, and $12 \mathrm{~cm}$ upper diameter in MPC soil; 4, 7, and $8 \mathrm{~cm}$ cavity depth/7, 16, and $18 \mathrm{~cm}$ upper diameter in RLV soil). Each hole was lined with a thin impermeable and flexible plastic film $(60 \mu \mathrm{m}$ thickness) and filled carefully with water to estimate the volume.

Developing new PTFs is an arduous task, so it is sensible to utilize already developed functions. Most existing PTFs have been developed from a large dataset of measured values $(\mathrm{N}>100)$ and are used for environmental modelling

Figure 1. Distribution in the experimental plots of in situ soil bulk density measurements applying three sampling methods (cylinder $[\mathrm{Cy}]$, excavation $[\mathrm{Ex}]$, and clod $[\mathrm{Cl})$, three sample sizes (small $[\mathrm{S}]$, medium $[\mathrm{M}]$, and large $[\mathrm{L}]$ ), and $\mathbf{1 0}$ pedotransfer functions (PTF).

\begin{tabular}{|c|c|c|c|c|c|c|c|c|c|c|c|c|c|}
\hline & & & & & & $0.5 \mathrm{~m}$ & & & & & & & \\
\hline PTF & SCy & & LEx & $\mathrm{LCl}$ & ng & $\mathrm{MCl}$ & $\mathrm{MCl}$ & & $\mathrm{SCy}$ & $\mathrm{LCl}$ & & LEx & SCy \\
\hline $\mathrm{SCl}$ & $\mathrm{LCl}$ & & LEx & SEx & & MEx & LCy & & $\mathrm{LCl}$ & MEx & & LCy & MCy \\
\hline $\mathrm{MCy}$ & $\mathrm{MCy}$ & $\bar{z}$ & $\mathrm{SCl}$ & LCy & & PTF & $\mathrm{SCl}$ & $\bar{I}$ & SEx & $\mathrm{LCl}$ & & PTF & LEx \\
\hline $\mathrm{MCy}$ & $\mathrm{SCl}$ & $=$ & SEx & $\mathrm{SCl}$ & & $\mathrm{MCl}$ & MEx & $=$ & $\mathrm{SCy}$ & $\mathrm{MCy}$ & & PTF & LEx \\
\hline $\mathrm{SCl}$ & SCy & $\underline{\xi}$ & PTF & LEx & ت् & $\mathrm{MCl}$ & SEx & 寻 & MEx & MEx & $\bar{g}$ & PTF & $\mathrm{LCl}$ \\
\hline $\mathrm{LCl}$ & $\mathrm{SCl}$ & & $\mathrm{MCl}$ & LEx & 光 & $\mathrm{MCl}$ & SEx & & $\mathrm{MCy}$ & PTF & ¿ & MEx & MCy \\
\hline SEx & $\mathrm{MCl}$ & & SEx & PTF & & SEx & MEx & & LEx & $\mathrm{SCy}$ & & $\mathrm{MCl}$ & MEx \\
\hline LCy & SEx & & LCy & LCy & & $\mathrm{SCl}$ & $\mathrm{SCy}$ & & $\mathrm{SCl}$ & $\mathrm{MCl}$ & & PTF & MCy \\
\hline $\mathrm{SCl}$ & LCy & & $\mathrm{MCl}$ & LEx & & $\mathrm{MCy}$ & LCy & & LCy & $\mathrm{LCl}$ & & $\mathrm{LCl}$ & $\mathrm{LCl}$ \\
\hline SCy & SEx & & $\mathrm{SCy}$ & LCy & & LEx & MEx & & MEx & $\mathrm{MCy}$ & & SCy & PTF \\
\hline
\end{tabular}


where measured $\rho_{\mathrm{b}}$ data are lacking. Here, 10 PTFs that require mainly fine soil particles $(<2 \mathrm{~mm})$ and organic matter (OM) content were chosen from the literature (Table 1). For example, the function by Rawls (1983) has been successfully used for Australian (Tranter et al., 2007), European (Hollis et al., 2012), and tropical soils (Minasny and Hartemink, 2011). The advantage of using the Rawls relationship is that the mineral bulk density $\left(\rho_{\mathrm{m}}\right)$ can be defined for each soil type, and the variation in soil $\mathrm{C}$ can be incorporated independently. Consequently, SOM content by loss-on-ignition at $400{ }^{\circ} \mathrm{C}$ (Sadzawka et al., 2004), soil particle size analysis (Bouyoucos hydrometer method), soil particle density (pycnometers), and soil water retention with conventional pressure plate techniques were determined (Sandoval et al., 2012) for randomly selected samples (10 replicates) extracted from each of our field plots (Table 2).

The Shapiro-Wilk and Anderson-Darling tests $(\alpha=5 \%)$, which are reported to be powerful statistic tools in studies similar to this (Razali and Wah, 2011) were used to check data normality. When data fail to satisfy one of these tests, an appropriate transformation must be applied. Finally, ANOVA and Tukey-Kramer tests allowed comparison of methods and sample sizes.

\section{RESULTS AND DISCUSSION}

Some relevant properties of selected soils are included in Table 2. As they have the same parent material, the two soils show similar particle density $\left(\rho_{p}\right)$. Besides, although other soil properties differed, as a result of soil management and conventional tillage, the observed OM content was low in both soils.

Bulk density $\left(\rho_{\mathrm{b}}\right)$ varies with the packing of the soil particles and wide range for a particular texture indicates that other factors (such as OM and compaction history) have an important influence on this property. Except volcanic soils and peaty soils, coarse-textured soils pack more closely with typical values higher than $1.4 \mathrm{Mg} \mathrm{m}^{-3}$, while fine-textured soils tend to bridge and cannot pack as tightly, giving values below 1.4 $\mathrm{Mg} \mathrm{m}^{-3}$ (Chan, 2005).

For all methods assessed, in the coarse-textured soil (RLV) the variation in $\rho_{\mathrm{b}}$ values tended to decrease with increasing sample size (Figure 2), but increased variation in $\rho_{\mathrm{b}}$ values with increasing sample size was observed in the fine-textured soil (MPC). On the other hand, fine-textured soils present a higher $\left(0.17\right.$ to $\left.0.04 \mathrm{Mg} \mathrm{m}^{-3}\right)$ dispersion in $\rho_{\mathrm{b}}$ values than for coarse-textured ( 0.09 to $0.03 \mathrm{Mg} \mathrm{m}^{-3}$ ) soil.

Table 1. The 10 pedotransfer functions used for determining soil bulk density in this study.

\begin{tabular}{|c|c|c|c|c|}
\hline Code & Pedotransfer function & Reference/Location & $\mathrm{R}^{2}$ & $\mathrm{n}$ \\
\hline E57 & $\rho_{\mathrm{b}}=1.2498-0.487 O M+0.063 C+0.0034 S$ & Eschner et al., 1957/USA & 0.49 & 134 \\
\hline R83 & $\rho_{\mathrm{b}}=\frac{100}{\frac{O M}{\rho_{O M}}+\frac{100-O M}{\rho_{m}}}$ & Rawls, 1983/USA & - & 2721 \\
\hline $\mathrm{T} \& \mathrm{H}$ & $\rho_{\mathrm{b}}=1.578-0.054 O C-0.006 \mathrm{Si}-0.004 C$ & Tomasella and Hodnett, 1998/Brazil & 0.60 & 613 \\
\hline B98 & $\rho_{\mathrm{b}}=1.398-0.0047 C-0.042 O C$ & Bernoux et al., 1998/Brazil & 0.50 & 323 \\
\hline L00 & $\rho_{\mathrm{b}}=1.7040-0.0031 S i+0.0026 C-0.1124 O C$ & Leonaviciute, 2000/Lithuania & 0.83 & 140 \\
\hline K02 & $\rho_{\mathrm{b}}=\mathrm{e}^{0.3130-0.1910 O C+0.0210 C-0.0005 C^{2}-0.0043 S i}$ & Kaur et al., 2002/India & 0.62 & 224 \\
\hline Dex & $\rho_{\mathrm{b}}=\frac{1}{0.5900+0.0016+0.0253 O M}$ & Dexter, 2004/Germany & $\begin{array}{l}0.35 \\
0.78\end{array}$ & $\begin{array}{l}28 \\
91\end{array}$ \\
\hline \multirow[t]{4}{*}{ R04 } & $\begin{array}{l}\rho_{\mathrm{b}}=1.36411+0.185628\left(0.0845397+0.701658 \mathrm{w}-0.614038 \mathrm{w}^{2}-1.18871 \mathrm{w}^{3}+\right. \\
0.00991862 \mathrm{y}-0.301816 \mathrm{wy}-0.153337 \mathrm{w}^{2} \mathrm{y}-0.0722421 \mathrm{y}^{2}+0.392736 \mathrm{wy} \mathrm{y}^{2}+0.0886315 \mathrm{y}^{3} \\
-0.601301 \mathrm{z}+0.651673 \mathrm{wz}-1.37484 \mathrm{w}^{2} \mathrm{z}+0.298823 \mathrm{yz}-0.192686 \mathrm{wyz}+0.0815752 \mathrm{y}^{2} \mathrm{z}- \\
\left.0.0450214 \mathrm{z}^{2}-0.179529 w \mathrm{w}^{2}-0.0797412 \mathrm{yz}^{2}+0.00942183 \mathrm{z}^{3}\right)\end{array}$ & Rawls et al., 2004/USA & - & 2100 \\
\hline & $\mathrm{x}=-1.2141+4.23123 \mathrm{~S} ; \quad \mathrm{y}=-1.70126+7.55319 C$ & & & \\
\hline & $z=-1.55601+0.5070940 M$ & & & \\
\hline & $\begin{array}{l}w=-0.0771892+0.256629 x+0.256704 x^{2}-0.140911 x^{3}-0.0237361 y-0.098737 x^{2} y- \\
0.140381 y^{2}+0.0140902 x y^{2}+0.0287001 y^{3}\end{array}$ & & & \\
\hline $\mathrm{H} 12 \mathrm{c}$ & $\rho_{\mathrm{b}}=0.808+0.824 e^{-0.2780 C}+0.001 S a-0.001 C$ [cultivated soils] & Hollis et al., 2012/Europe & 0.62 & 333 \\
\hline H12 & $\rho_{\mathrm{b}}=0.6979+0.7506 e^{-0.2304}+0.0009 \mathrm{Sa}-0.0005 C$ [other soils] & & 0.63 & 925 \\
\hline
\end{tabular}

n: Sampled soils, $\rho_{\mathrm{b}}$ : soil bulk density $\left(\mathrm{Mg} \mathrm{m}^{-3}\right), O M / O C$ : gravimetric organic matter/C content $(\%), \rho_{\mathrm{OM}}:$ average organic matter bulk density $\left(0.224 \mathrm{Mg} \mathrm{m}^{-3}\right)$, $\rho_{\mathrm{m}}$ : bulk density of mineral soil fraction $\left(\mathrm{Mg} \mathrm{m}^{-3}\right), S, S i$, and $C$ : gravimetric contents $(\%)$ of sand, silt and clay particles, respectively.

Table 2. Some basic properties $(n=3)$ of the well aggregated, coarse-textured Rinconada de Lo Vial (RLV) and massive, fine-textured Mapocho (MPC) soils.

\begin{tabular}{|c|c|c|c|c|c|c|c|}
\hline Pedon & $\mathrm{S}$ & $\mathrm{C}$ & $\mathrm{Si}$ & SOC & $\mathrm{W}_{33}$ & $\mathrm{~W}_{1500}$ & $\rho_{\mathrm{p}}$ \\
\hline & \multicolumn{6}{|c|}{$\%$} & $\mathrm{Mg} \mathrm{m}^{-3}$ \\
\hline RLV & $69.8 \pm 1.7$ & $13.6 \pm 0.5$ & $16.7 \pm 1.6$ & $0.8 \pm 0.1$ & $17.0 \pm 1.0$ & $9.0 \pm 1.0$ & $2.60 \pm 0.01$ \\
\hline MPC & $38.2 \pm 2.7$ & $28.5 \pm 1.1$ & $33.3 \pm 2.4$ & $1.7 \pm 0.4$ & $26.7 \pm 1.9$ & $12.1 \pm 1.1$ & $2.62 \pm 0.01$ \\
\hline
\end{tabular}

$S$ : Sand, $C$ : clay, Si: silt; SOC: soil organic carbon; $W_{33}$ and $W_{1500}$ : gravimetric water contents of soil at 33 and $1500 \mathrm{kPa} ; \rho_{\mathrm{p}}$ : soil particle density. 
Figure 2. Box plots of soil bulk density values according to sampling methods (cylinder $[\mathrm{Cy}]$, excavation $[\mathrm{Ex}]$, and clod $[\mathrm{CI}]$ ), and sample sizes (small $[\mathrm{S}]$, medium $[\mathrm{M}]$, and large $[\mathrm{L}]$ ) in fine-textured (left) and coarse-textured (right) soils of central Chile.

Fluventic Haploxeroll (Mapocho soil)

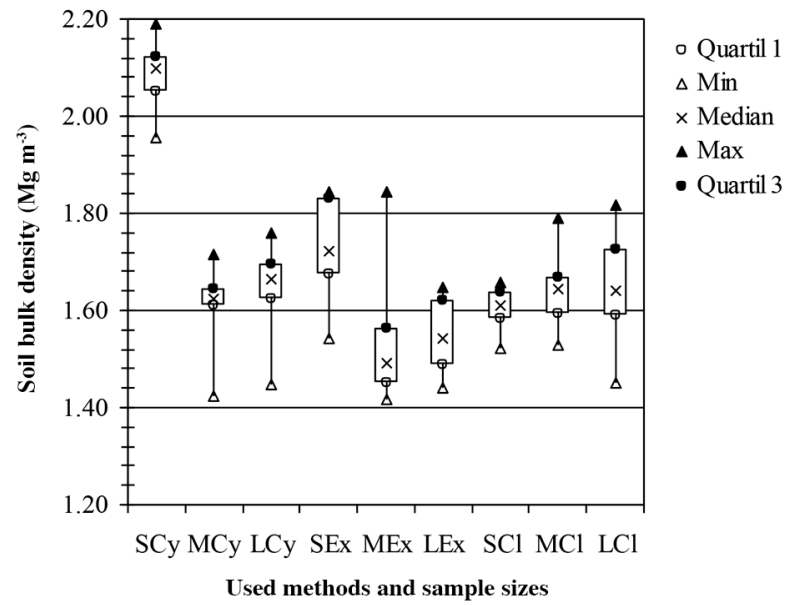

Fluventic Haploxerept (Rinconada Lo Vial soil)

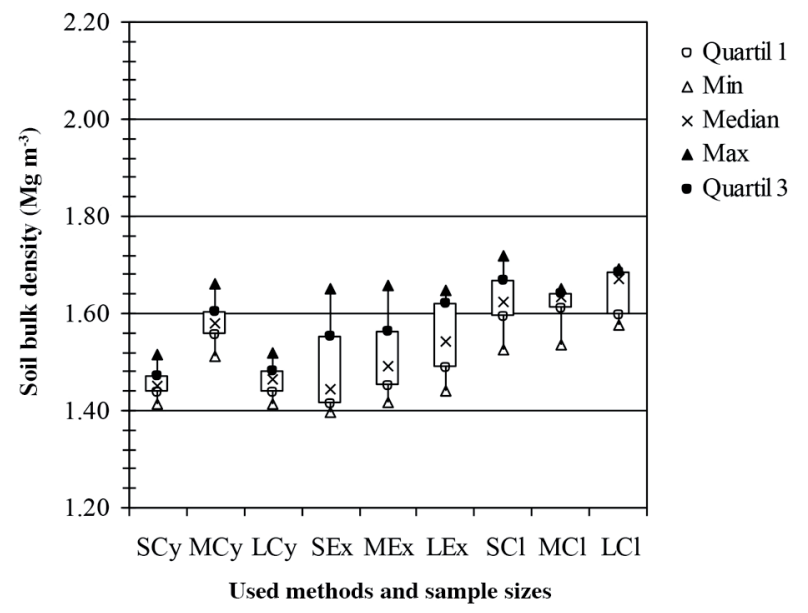

Although the coring process itself can cause friction and lead to soil compression (Hartge and Ellies, 1999; PageDumroese et al., 1999), the small-cylinder (SCy) method showed a remarkably high mean value of $\rho_{\mathrm{b}}$ on MPC soil, denoting extreme method-induced soil shattering and compaction. In contrast, expected values were found in the coarse-textured soil (RLV), with the large-clod ( $\mathrm{LCl}$ ) method giving the highest and SCy the lowest mean value (Figure 2). It is known that the clod procedure does not account for inter-aggregate pores or cracks and thus gives higher values than other direct procedures, but this was more apparent in the structured soil (RLV) than in the massive fine-textured soil (MPC). Another concern is that $\rho_{\mathrm{b}}$ values may be higher because sampling could be biased toward the collection of firmer, more compact clods capable of withstanding disturbance during transport and measurement (Naeth et al., 1991).

After $\rho_{\mathrm{b}}$ data normality verification, nonsignificant differences between methods and sample sizes assessed for the fine-textured soil (MPC) were detected, with the exception of SCy (Table 3). For the coarse-textured soil (RLV), there were nonsignificant differences between sizeexcavation and size-clod treatments, but medium-cylinder (MCy) method differed from other cylinder sizes. Moreover, the clod technique tended to differ from the other methods (Tables 3 and 4), with generally higher values.

It is conceivable that some of the variation in $\rho_{p}$ values observed between methods could have been caused by differences in sample location. However, as stated by several authors (Page-Dumroese et al., 1999), all methods differ in accuracy (success in estimating the true value of $\rho_{\mathrm{b}}$ ), precision (clustering of sample estimates about their own mean), and bias (the systematic distortion of estimates for the true value). In the present work, the excavation method gave less precision (higher variation) for both soils analyzed, which was attributed to non-uniformity in the original samples.

When applied to the coarse-textured RLV soil, a best fit of some PTFs to measured data was observed (Figure 3, right), but another five PTFs, corresponding to studies in tropical regions, clearly underestimated (negative mean errors) the $\rho_{\mathrm{b}}$ values (Figure 3, left). The Tukey-Kramer test (results not included) showed that all $\rho_{\mathrm{b}}$ values measured with the excavation and clod methods were nonsignificantly different to four existing PTFs (Eschner et al., 1957; Rawls, 1983; Dexter, 2004; Hollis et al., 2012) for cultivated soils and two

Table 3. Absolute values of mean differences between sample methods and sizes, according to the Tukey-Kramer test, for a finetextured soil in central Chile.

\begin{tabular}{|c|c|c|c|c|c|c|c|c|c|}
\hline \multicolumn{10}{|c|}{ Mapocho soil (Fluventic Haploxeroll) } \\
\hline & SCy & MCy & LCy & SEx & MEx & LEx & $\mathrm{SCl}$ & $\mathrm{MCl}$ & $\mathrm{LCl}$ \\
\hline SCy & - & & & & & & & & \\
\hline $\mathrm{MCy}$ & $0.4782^{*}$ & - & & & & & & & \\
\hline $\mathrm{LCy}$ & $0.4316^{*}$ & 0.0466 & - & & & & & & \\
\hline SEx & $0.3526^{*}$ & 0.1256 & 0.0790 & - & & & & & \\
\hline MEx & $0.4463^{*}$ & 0.0319 & 0.0147 & 0.0937 & - & & & & \\
\hline LEx & $0.4629^{*}$ & 0.0153 & 0.0313 & 0.1103 & 0.0166 & - & & & \\
\hline $\mathrm{SCl}$ & $0.4816^{*}$ & 0.0034 & 0.0500 & 0.1290 & 0.0353 & 0.0187 & - & & \\
\hline $\mathrm{MCl}$ & $0.4493^{*}$ & 0.0289 & 0.0177 & 0.0967 & 0.0030 & 0.0136 & 0.0323 & - & \\
\hline $\mathrm{LCl}$ & $0.4441^{*}$ & 0.0341 & 0.0125 & 0.0915 & 0.0022 & 0.0188 & 0.0375 & 0.0052 & - \\
\hline
\end{tabular}

*Values higher than Tukey-Kramer least significant difference (0.1408) denote differences between paired data. Methods (Cy: cylinder, Ex: excavation, $\mathrm{Cl}$ : clod) and sample sizes (S: small, M: medium, L: large). 
Table 4. Absolute values of mean differences between sample methods and sizes, according to Tukey-Kramer test, for a coarsetextured soil in central Chile.

\begin{tabular}{|c|c|c|c|c|c|c|c|c|c|}
\hline \multicolumn{10}{|c|}{ Rinconada Lo Vial soil (Fluventic Haploxerept) } \\
\hline & $\mathrm{SCy}$ & $\mathrm{MCy}$ & LCy & SEx & MEx & LEx & $\mathrm{SCl}$ & $\mathrm{MCl}$ & LC \\
\hline SCy & - & & & & & & & & \\
\hline MCy & $0.1246^{*}$ & - & & & & & & & \\
\hline $\mathrm{LCy}$ & 0.0075 & $0.1171^{*}$ & - & & & & & & \\
\hline SEx & 0.0305 & $0.0941^{*}$ & 0.0230 & - & & & & & \\
\hline MEx & 0.0539 & 0.0708 & 0.0463 & 0.0234 & - & & & & \\
\hline LEx & $0.0928^{*}$ & 0.0318 & $0.0853^{*}$ & 0.0623 & 0.0390 & - & & & \\
\hline $\mathrm{SCl}$ & $0.1677^{*}$ & 0.0430 & $0.1602^{*}$ & $0.1372^{*}$ & $0.1138^{*}$ & 0.0748 & - & & \\
\hline $\mathrm{MCl}$ & $0.1593^{*}$ & 0.0347 & $0.1518^{*}$ & $0.1288^{*}$ & $0.1055^{*}$ & 0.0665 & 0.0084 & - & \\
\hline $\mathrm{LCl}$ & $0.1911^{*}$ & 0.0665 & $0.1836^{*}$ & $0.1606^{*}$ & $0.1372^{*}$ & $0.0983^{*}$ & 0.0234 & 0.0318 & - \\
\hline
\end{tabular}

*Values higher than Tukey-Kramer least significant difference (0.0852) denote differences between paired data. Methods (Cy: cylinder, Ex: excavation, $\mathrm{Cl}$ : clod) and sample sizes (S: small, M: medium, L: large).

other functions (Leonaviciute, 2000; Rawls et al., 2004), respectively. Besides, $\rho_{\mathrm{b}}$ values determined with small and large cylinders corresponded to the functions of Eschner et al. (1957) and Rawls (1983), while those determined with medium cylinders corresponded to three of the selected PTFs (Leonaviciute, 2000; Dexter, 2004; Rawls et al., 2004).

On the other hand, the selected PTFs showed large differences in performance when applied to the fine-textured MPC soil (Figure 4), where their poor aggregation was attributable to very limited predictive potential $\left(R^{2}\right)$ of published $\rho_{\mathrm{b}}$ PTFs, which poorly capture the soil property variability (Kaur et al., 2002). In fact, according to the Tukey-Kramer test, only $\rho_{\mathrm{b}}$ values measured with the MCy and those obtained with the Leonaviciute (2000) function did not show significant differences.

Thus, it is not clear whether a particular PTF performs better than others because of: (i) differences between the datasets used to derive PTFs, (ii) differences between the algorithms used in developing PTFs, or (iii) differences in the input attributes used. Several authors (Kaur et al., 2002; De Vos et al., 2005) have concluded that existing PTFs display large differences in performance and should be used with care, especially when applied in environments other than those in which they were calibrated. The anomalous behavior of the published PTFs used in this study suggests that the mineralogy of the validation soil samples may have been different from that of the soils from which the PTFs were developed. On the other hand, $\rho_{\mathrm{b}}$ is largely controlled by SOM in a non-linear relationship, while soil particles have a linear effect on this property (Al-Qinna and Jaber, 2013). Further studies are needed to incorporate soil structure as an input parameter to derive PTFs.

Pedo-transfer functions are useful solutions for investigation of different aspects of the physical quality of soils that do not have readily-available measured data, but this study demonstrated the poor performance of some published PTFs when applied to contrasting alluvial Chilean soils (Figure 5). This raises concerns that the predictive ability of even the better models may not be adequate and that it is necessary to define local PTFs that address the complexity of the soil resource throughout Chile.

\section{CONCLUSIONS}

Only the aggregated, coarse-textured soil (RLV, Rinconada Lo Vial) studied here showed a tendency for decreased variation in soil bulk density $\left(\rho_{\mathrm{b}}\right)$ values obtained by three direct methods with increasing sample size. There were nonsignificant differences between excavation sizes or clod sizes, but medium cylinders differed from other cylinder sizes and the clod technique tended to differ from the excavation and cylinder methods.

Considering these alluvial soils of central Chile, only large clods are recommended for massive fine-textured soils and optionally the excavation method for structured finetextured soils. However, if clods are prone to disturbance and difficult to handle, then care should be taken to ensure that the clods are representative of the soil horizon being sampled and that there has been no deformation during collection and transport. Cylinders (H/D = 1 to 2 ) can be used in coarse-textured soils, but excavations must be preferred if soil material is non-cohesive or abundant coarse fragments (>2 mm diameter particles) are present. Excavation is an appealing alternative because it allows flexibility in the size of soil samples to be collected.

A remarkably high mean value of $\rho_{\mathrm{b}}$ was observed on the massive, fine-textured soil (MPC, Mapocho) with small cylinders, denoting extreme method-induced soil compaction and the impact of conventional tillage at the site. However, no other significant differences between the methods and sample sizes assessed were detected.

Most the 10 pedotransfer functions (PTFs) applied to the aggregated, coarse-textured alluvial soil (RLV) gave only comparable estimates of $\rho_{\mathrm{b}}$, whereas when applied to the fine-textured and unstructured soil (MPC) a greater number of them differed from each other. Thus, when $\rho_{\mathrm{b}}$ was estimated from the selected functions big uncertainty is observed.

The PTFs based only on predictors that are easy to measure (soil organic matter, clay, silt, sand in the soil matrix) show evident limitations when applied to Chilean soils, even within the range of validity for which they had been derived. This indicates that the performance of PTFs is influenced by other factors (geographical source of datasets used for 
Figure 3. Observed and predicted soil bulk density relative to the 1:1 reference line by dataset of a coarse-textured soil of central Chile (sandy loam, Rinconada Lo Vial soil series) and different pedotransfer functions (for pedotransfer function codes see Table 1).
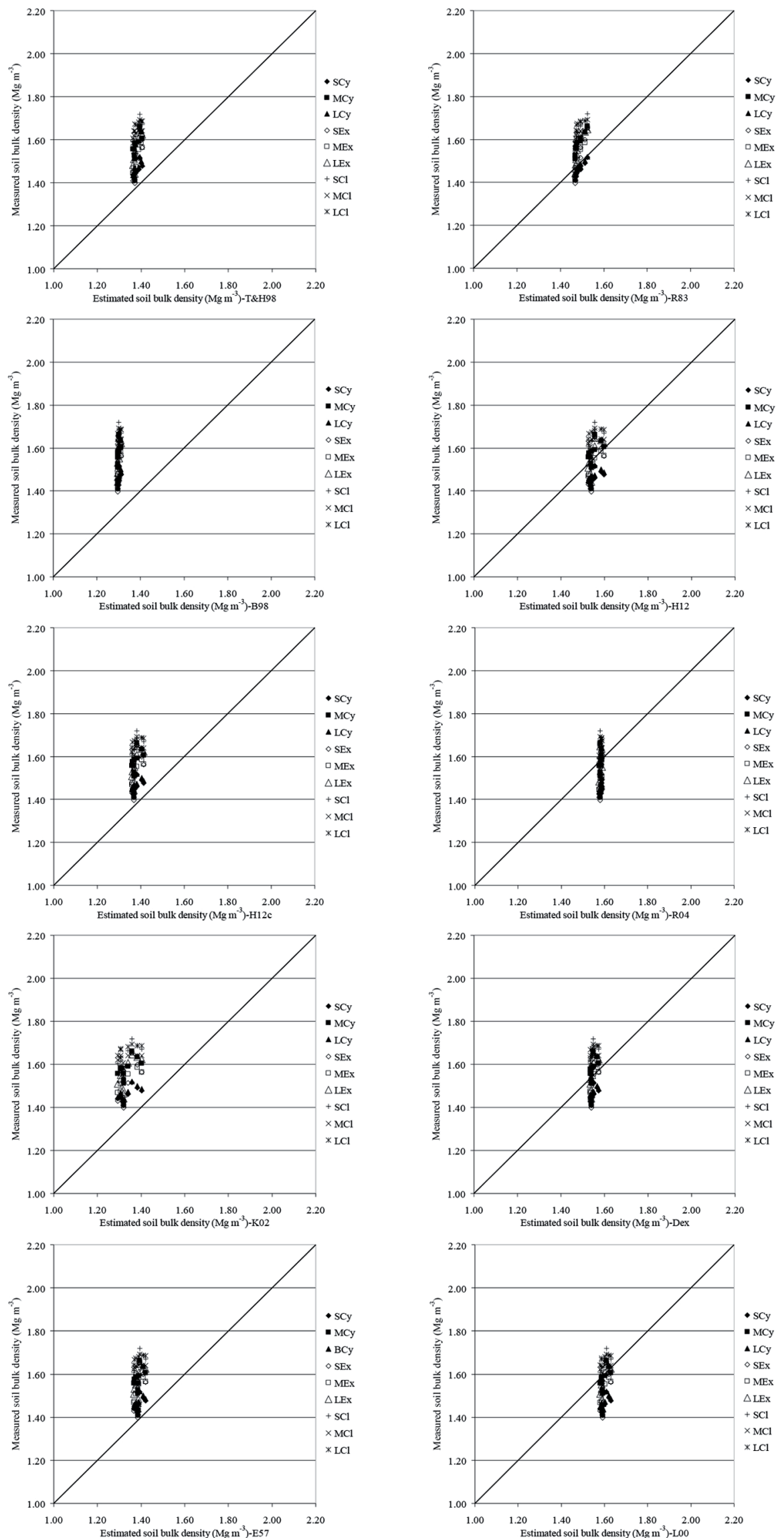
Figure 4. Observed and predicted soil bulk density relative to the 1:1 reference line by dataset for a fine-textured soil of central Chile (clay loam, Mapocho soil series) and different pedotransfer functions (for pedotransfer function codes see Table 1).
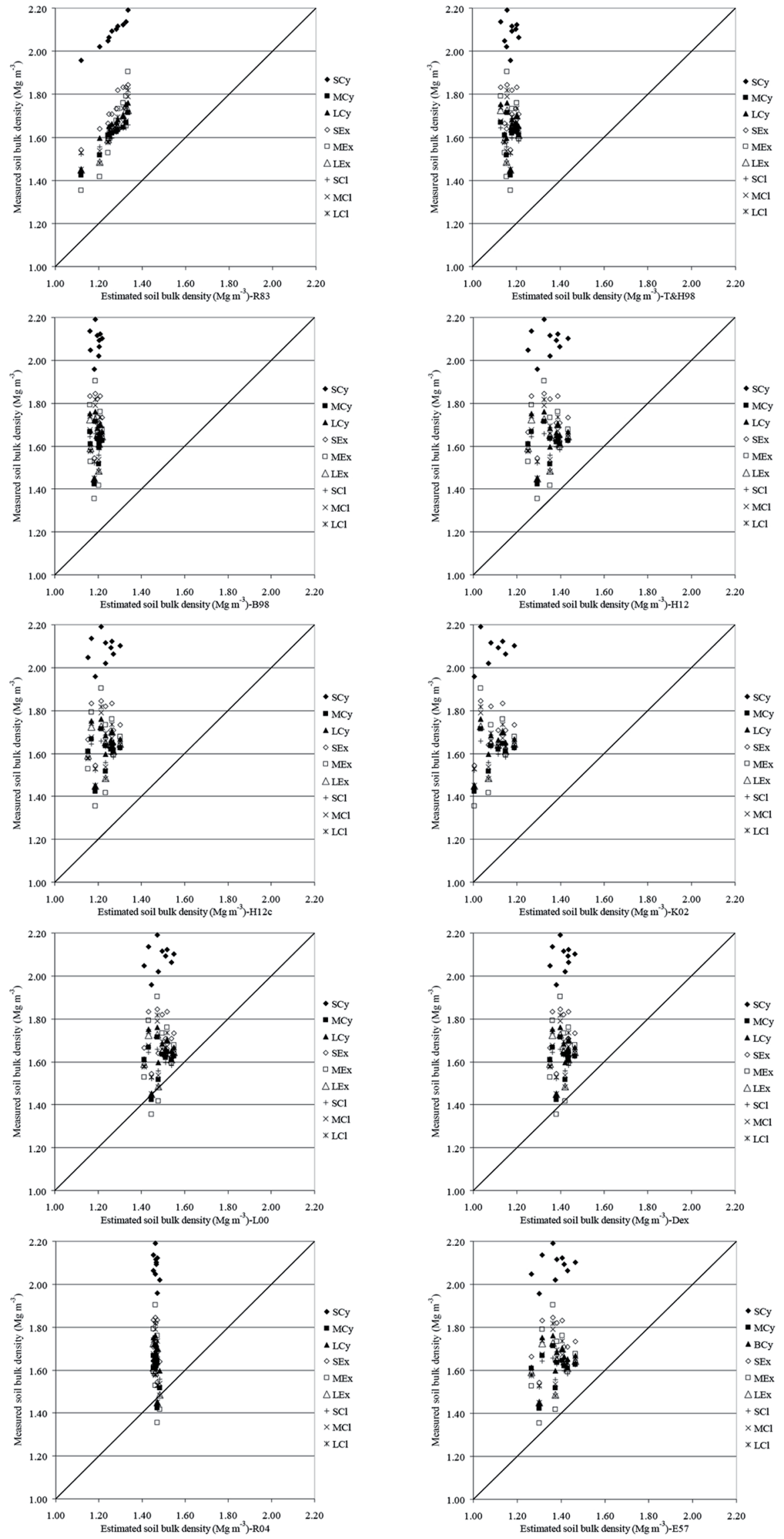
Figure 5. Mean soil bulk density values $(\mathrm{n}=\mathbf{1 0}, \pm$ standard deviation) obtained by 10 different pedotransfer functions on two soils (Rinconada Lo Vial [RLV] and Mapocho [MPC]) of central Chile (for pedotransfer function codes see Table 1).

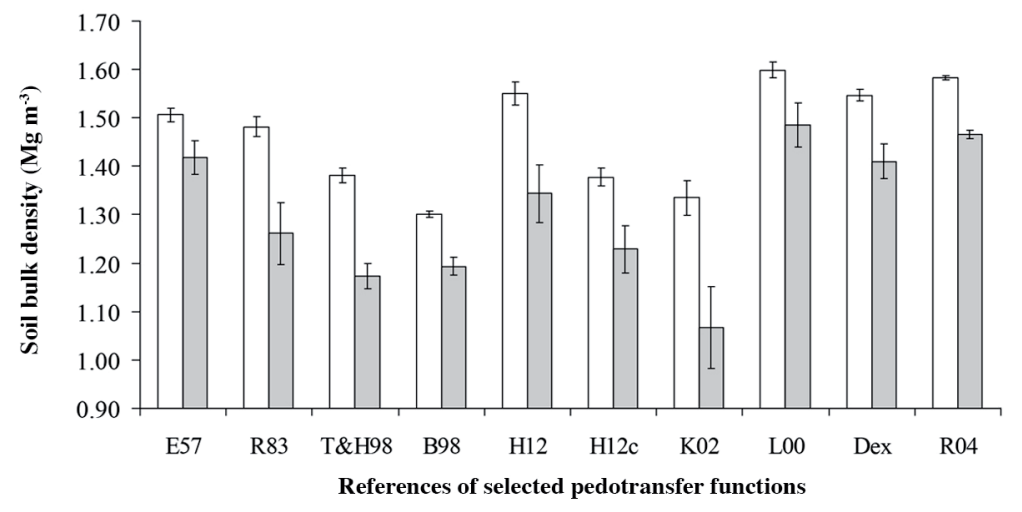

$\square$ MPC (Fluventic Haploxeroll)

$\square$ RLV (Fluventic Haploxerept)

their development, management and structure differences in measurement techniques, or other dependencies) that were not considered here.

Finally, although priority must still be given to in situ methods for measuring $\rho_{\mathrm{b}}$ in studies at field level, it appears necessary to define a set of locally calibrated PTFs that address the complexity of the soil resource throughout Chile.

\section{REFERENCES}

Al-Qinna, M.I., and S.M. Jaber. 2013. Predicting soil bulk density using advanced pedotransfer functions in an arid environment. Transactions of the American Society of Agricultural and Biological Engineers 56:963-976. doi:http://dx.doi.org/10.13031/ trans.56.9922.

Assouline, S. 2011. Bulk density of soils and impact on their hydraulic properties. p. 95-100. In Glinski, J., J. Horabik, and J. Lipiec (eds.) Encyclopedia of agrophysics. Springer, Dordrecht, The Netherlands.

Bernoux, M., C. Cerri, D. Arrouays, and C. Jolivet. 1998. Bulk densities of Brazilian Amazon soils related to other soil properties. Soil Science Society of America Journal 62:743-749. doi:10.2136/sssaj1998.03615995006200030029x.

Brye, K.R., T.L. Morris, D.M. Miller, S.J. Formica, and M.A Van Eps. 2004. Estimating bulk density in vertically exposed stoney alluvium using a modified excavation method. Journal of Environmental Quality 33:1937-1942. doi:10.2134/ jeq2004.1937.

Chan, K.Y. 2005. Bulk density. p. 191-193. In Lal, R. (ed.) Encyclopedia of soil science. Marcel Dekker, New York, USA.

Cresswell, H.P., and G.J. Hamilton. 2002. Bulk density and pore space relations. p. 35-58. In McKenzie, N.J., H. Cresswell, and K. Coughlan (eds.) Soil physical measurement and interpretation for land evaluation. A laboratory handbook. CSIRO Publishing, Melbourne, Australia.

De Vos, B., M. Van Meirvenne, P. Quataert, J. Deckers, and B. Muys. 2005. Predictive quality of pedotransfer functions for estimating bulk density of forest soils. Soil Science Society of America Journal 69:500-510. doi:10.2136/sssaj2005.0500.

Dexter,A.R. 2004. Soil physical quality. Part I. Theory, effects of soil texture, density, and organic matter, and effects on root growth. Geoderma 120:201-214. doi:10.1016/j.geoderma.2003.09.004.

Donatelli, M., J.H.M. Wösten, and G. Belocchi. 2004. Methods to evaluate pedotransfer functions. Development in Soil Science 30: 357-411. doi:10.1016/S0166-2481(04)30006-1.
Drewry, J.J. 2006. Natural recovery of soil physical properties from treading damage of pastoral soils in New Zealand and Australia: a review. Agriculture, Ecosystems and Environment 114:159168. doi:10.1016/j.agee.2005.11.028.

Eschner,A.R.,B.O.Jones, and R.C.Moyle. 1957.Physical properties of 134 soils in six northeastern states. Station Paper NE-89. U.S. Department of Agriculture, Forest Service, Northeastern Forest Experiment Station, Newtown Square, Pennsylvania, USA.

Grossman, R.B., and T.G. Reinsch. 2002. Bulk density and linear extensibility. p. 201-228. In Dane, J.M., and G.C. Topp (eds.) Methods of soil analysis. Part 4. Physical methods. Soil Science Society of America, Madison, Wisconsin, USA.

Hartge, K.H., y A. Ellies. 1999. El rol de la física del suelo en la producción agrícola. AgroSur 27:43-56.

Helliwell, J.R., C.J. Sturrock, K.M. Grayling, S.R. Tracy, R.J. Flavel, I.M. Young, et al. 2013. Applications of X-ray computed tomography for examining biophysical interactions and structural development in soil systems: a review. European Journal of Soil Science 64:279-297. doi:10.1111/ejss.12028.

Hollis, J.M., J. Hannam, and P.H. Bellamy. 2012. Empiricallyderived pedotransfer functions for predicting bulk density in European soils. European Journal of Soil Science 63:96-109. doi:10.1111/j.1365-2389.2011.01412.x.

Horn, R., T. Way, and J. Rostek. 2003. Effect of repeated tractor wheeling on stress/strain properties and consequences on physical properties in structured arable soils. Soil and Tillage Research 73:101-106. doi:10.1016/S0167-1987(03)00103-x.

Hu, W., M.A. Shao, and B. Si. 2012. Seasonal changes in surface bulk density and saturated hydraulic conductivity of natural landscapes. European Journal of Soil Science 63:820-830. doi:10.1111/j.1365-2389.2012.01479.x.

Kaur, R., S. Kumar, and H. Gurung. 2002. A pedo-transfer function (PTF) for estimating soil bulk density from basic soil data and its comparison with existing PTFs. Australian Journal of Soil Research 40:847-857. doi:10.1071/SR01023.

Leonaviciute, N. 2000. Predicting soil bulk and particle densities by pedotransfer functions from existing soil data in Lithuania. Geografijos Metrastis 33:317-330.

Liu, X., T. Ren, and R. Horton. 2008. Determination of soil bulk density with thermo-time domain reflectometry sensors. Soil Science Society of America Journal 72:1000-1005. doi:10.2136/ sssaj2007.0332.

Minasny, B., and A.E. Hartemink. 2011. Predicting soil properties in the tropics. Earth Science Reviews 106:52-62. doi:10.1016/j. earscirev.2011.01.005.

Montecinos, A., and P. Aceituno. 2003. Seasonality of the ENSOrelated rainfall variability in Central Chile and associated circulation anomalies. Journal of Climate 16:281-296. doi:10.1175/1520-0442(2003)016<0281:SOTERR>2.0 .CO;2. 
Naeth, M., D. White, D. Chanasyk, T. Macyk, C. Powter, and D. Thacker. 1991. Soil physical properties in reclamation. Alberta Land Conservation and Reclamation Council (Reclamation Research Technical Advisory Committee) RRTAC Report 91-4. Edmonton, Alberta, Canada.

Page-Dumroese, D.S., M.F. Jurgensen, R.E. Brown, and G.D. Mroz. 1999. Comparison of methods for determining bulk densities of rocky forest soils. Soil Science Society of America Journal 63:379-383. doi:10.2136/sssaj1999.03615995006300020016x.

Pansu, M., J. Gautheyrou, and J.Y. Loyer. 2001. Soil analysis - Sampling, instrumentation and quality control. Balkema Publishers, Rotterdam, The Netherlands

Pizarro, R., R. Valdés, P. García-Chevesich, C. Vallejos, C. Sangüesa, C. Morales, et al. 2012. Latitudinal analysis of rainfall intensity and mean annual precipitation in Chile. Chilean Journal of Agricultural Research 72:252-261. dx.doi.org/10.4067/S071858392012000200014.

Rawls, W. 1983. Estimating soil bulk density from particle size analysis and organic matter content. Soil Science 135:123-125. doi:10.1097/00010694-198302000-00007.

Rawls, W., A. Nemes, and Y.A. Pachepsky. 2004. Effect of soil organic carbon on soil hydraulic properties. Development in Soil Science 30:95-114. doi:10.1016/S0166-2481(04)30006-1.

Razali, N.M., and Y.B. Wah. 2011. Power comparisons of ShapiroWilk, Kolmogorov-Smirnov, Lilliefors and Anderson-Darling tests. Journal of Statistical Modelling and Analytics 2(1):21-33.

Rossi, A.M., D.R. Hirmas, R.C. Graham, and P.D. Sternberg. 2008. Bulk density determination by automated three-dimensional laser scanning. Soil Science Society of America Journal 72:15911593. doi:10.2136/sssaj2008.0072n.

Sadzawka, A., M.A. Carrasco, R. Grez, y M.L. Mora. 2004. Métodos de análisis recomendados para los suelos chilenos. Comisión de Normalización y Acreditación, Sociedad Chilena de la Ciencia del Suelo, Santiago, Chile.
Sandoval, M., J. Dörner, O. Seguel, J. Cuevas, y D. Rivera. 2012. Métodos de análisis físicos de suelos. Departamento de Suelos y Recursos Naturales Publicación $\mathrm{N}^{\circ}$ 5. Universidad de Concepción, Chillán, Chile.

Siegel-Issem, C.M., J.A. Burger, R.F. Powers, F. Ponder, and S.C. Patterson. 2005. Seedling root growth as a function of soil density and water content. Soil Science Society of America Journal 69:215-226. doi:10.2136/sssaj2005.0215.

Soil Survey Staff. 2014. Key to soil taxonomy. $12^{\text {th }}$ ed. USDA, National Resources Conservation Service, National Soil Survey Center, Lincoln, Nebraska, USA

Throop, H., S. Archer, H.C. Monger, and S. Waltman. 2012. When bulk density methods matter: implications for estimating soil organic carbon pools in rocky soils. Journal of Arid Environments 77:66-71. doi:10.1016/j.jaridenv.2011.08.020.

Timm, L.C., L.F. Pires, K. Reichardt, R. Roveratti, J. Oliveira, and P. Bacchi. 2005. Soil bulk density evaluation by conventional and nuclear methods. Australian Journal of Soil Research 43:97-103. doi:10.1071/SR04054.

Tomasella, J., and M.G. Hodnett. 1998. Estimating soil water retention characteristics from limited data in Brazilian Amazonia. Soil Science 163:190-202 doi:10.1097/00010694199803000-00003.

Tranter, G., B. Minasny, A.B. McBratney, B. Murphy, N.J. McKenzie, M. Grundy, et al. 2007. Building and testing conceptual and empirical models for predicting soil bulk density. Soil Use and Management 23:437-443. doi:10.1111/j.14752743.2007.00092.x.

Zeng, C., Q. Wang, F. Zhang, and J.Zhang. 2013. Temporal changes in soil hydraulic conductivity with different soil types and irrigation methods. Geoderma 193/194:290-299. doi:10.1016/j. geoderma.2012.10.013. 